\title{
Research on Improving Citizens' Moral Quality and Civilization Quality from the Perspective of Socialist Core Values*
}

\author{
Lihua Huang \\ Fuzhou University of International Studies and Trade \\ Fuzhou, China 350200
}

\begin{abstract}
The popular identity for socialist core values is the need for the development of social practice. This paper also studies the socialist core values and the mechanism of improving citizens' moral quality and civilization quality, explores the concrete path of the integration of the socialist core values into moral quality and civilization quality of citizens. It is the enrichment and development of the ideological and political theories of the citizens.
\end{abstract}

Keywords-socialist core values; moral quality; civilization quality

\section{INTRODUCTION}

In the report of 19th National Congress of the Communist Party of China, it has emphasized: "We must nurture and practice socialist core values, and integrate socialist core values into all aspects of social development, and translate into people's emotional identity and behavioral habits." "We must strengthen ideological and moral construction. People have faith. The country has power. And the nation has hope." To this end, we must adhere to the guidance of Marxism, introduce theories of socialist core values, systems theory, communication studies, and management into the grass-roots people's ideological and political education, research and practice socialist core values, and enhance citizens' moral quality and civilization quality. This paper has sort out the main obstacles and internal mechanisms of the cultivation of socialist core values, citizen moral quality and civilization quality. Through the above theoretical research and empirical analysis, it can provide a basic theoretical framework and theoretical basis to better optimize socialist core values in the improvement of moral quality and civilization quality.

*Fund Project: 2017 Key Projects of the Fuzhou Socialism Theoretical System Research Center with Chinese Characteristics: Research on Implementing Socialist Core Values and Improving Citizens' Moral Quality and Civilization Quality (Project Number: 2017A06)

\section{THE SignIFICANCE OF PRACTICING SOCIALIST CORE VALUES AND IMPROVING CITIZENS' MORAL QUALITY AND CIVILIZATION QUALITY}

\section{A. The Mechanism of Improving Citizens' Moral Quality and Civilization Quality}

Based on socialist core values, the improvement of citizens' moral quality and civilization quality and the analysis of social investigations, how do socialist core values affect citizens' moral qualities and civilization qualities? How should it be analyzed and evaluated? What are the driving factors? Judging from the existing research, the research on the cultivation path of practicing socialist core values and improving citizens' moral quality and civilization quality is still in its infancy. Based on the previous research, the author will analyze the entire process of citizens' moral quality and civilization quality from ideological identification to practice transformation from the perspective of socialist core values, and discuss the improvement mechanism of moral quality and civilization quality of citizens under the background of practicing socialist core values.

\section{B. The Path to Deepen the Socialist Core Values}

The phenomenon of infiltration in the field of ideology and culture currently existing in society reflects the lack of socialist core values of citizens. The study of improving citizens' moral quality and civilization quality is conducive to play the leading role of socialist core values. It is directly related to the improvement of citizens' moral quality and civilization quality. To a certain extent, it is related to the country's future and destiny. It can make the contribution to the study on the practice of socialist core values, and the promotion path of citizens' moral quality and civilization quality.

\section{Providing Guidance for Carrying forward the Socialist Core Values}

Under the multicultural background of great social changes, great economic development, big collisions of ideas, and great cultural blending, different values and value choices have determined the future direction of society to a 
certain extent. The study of improving citizens' moral quality and civilization quality will be helpful to build the main battlefield for carrying forward socialist core values. It effectively explains the advanced nature of socialist core values, and promotes positive energy in citizen propaganda. Therefore, it has important practical guidance for carrying forward socialist core values and improving the moral quality and civilization quality of citizens.

\section{TO IMPLEMENT SOCIALIST CORE VALUES, AND IMPROVE MORAL QUALITY AND CIVILIZATION QUALITY OF CITIZEN}

The cultivation path of practicing socialist core values and improving citizens' moral quality and civilization quality mainly reflects the three dimensions of endogenous mechanism, exogenous mechanism and value mechanism. Among them, the endogenous mechanism is the premise, the exogenous mechanism is the foundation, and the value mechanism is the core. The synergy of three concepts has prompted the popular identity of socialist core values.

\section{A. Enhancing the Endogenous Mechanism of Citizens' Moral Quality and Civilization Quality}

The general spiritual needs of human beings are first moved with instinctive nature. Human needs are multidimensional. The psychologist Maslow's creativity divided the needs into five levels: physiology, safety, belonging and love, respect, and self-realization. Generally speaking, we divide the needs into two levels: material needs and spiritual needs. As a result, people's survival needs are to be satisfied with basic living materials such as food, clothing, housing, and transportation. Spiritual needs are the higher-level needs on the material-level. It embodies the cultural attributes of human beings. And it is an important dimension of human nature. Of course, the spiritual needs of human beings are also rich, colorful and clearly structured. It includes both the needs for education and reputation, as well as the needs for aesthetics and value realization. It has the low-level needs for belonging and love, and the high-level needs for values, noble moral sentiments. Therefore, in order to meet the high-level refined needs of human beings such as the concept of values, humans must engage in spiritual production in addition to material production. And they must seek out the core values of a society to enhance the moral quality and civilization quality of citizens and meet the spiritual needs of humans. Also, humans should build a common spiritual home and eliminate people's "troubles in the growth".

\section{B. Exogenous Mechanisms of Improving Citizens' Moral Quality and Civilization Quality}

Human values are reflections of social existence. Social existence is comprehensive and complex in shaping people's values. If there is no social factor, public recognition will not be achieved. Therefore, it is necessary to explore the exogenous mechanism of improving citizens' moral quality and civilization quality. According to the theories of psychology, sociology and other disciplines, popular identity is caused by the resonance effect of social expectations and the needs of social adaptation. Therefore, the social mechanism for improving citizens' moral quality and civilization quality is mainly reflected in the joint effects of social expectations (outside expectation) and public socialization needs (inner needs). It would be compatible with the recognition.

Based on the related knowledge of sociology, social psychology and other disciplines, and the background of socialist core values, the exogenous mechanism of promoting citizens' moral qualities and civilization quality is mainly manifested in the expectations or needs of improving citizen's moral quality and civilization quality and the intrinsic demands or needs in the process of mass socialization from the perspective of public recognition of socialist core values. The homogenous role of external expectation and internal need would promote public recognition.

In summary, the socialist core values are the internal needs of social development and promote the improvement of citizens' moral quality and civilization quality. The core values of a society are like social fusion and agglutination. Any society needs core values to unify ideas, understanding, and people's hearts. This is an important reason for an orderly operation and normal operation of society.

\section{The Value Mechanism of Improving Citizens' Moral Quality and Civilization Quality}

It is possible for the public to identify the socialist core values. Why will the public agree with it? It is determined by the value of the socialist core values. To this end, the value theory is used to analyze the value mechanism of promoting citizens' moral quality and civilization quality, which mainly includes two dimensions: the value of the attributes of things and the value of the existence of things. This requires not only exploring the value of improving moral quality and civilization quality of citizens, but also analyzing the extent to which citizens' moral qualities and civilized qualities are met to meet the actual needs of the public. The essence of value is mainly reflected in the "specific relationship between the attributes of the object and the subject". The value mechanism that promotes the civilization quality and moral quality of citizens is mainly characterized by the two aspects of socialist core values such as the improvement of the scientific quality of citizens' moral qualities and civilization qualities, and satisfying the needs of the general public for survival and development.

The value mechanism of improving citizens' moral quality and civilization quality is mainly reflected in two dimensions such as the scientific nature of the content, and satisfying the needs of the people's survival and development. Specifically, on the one hand, the content of promoting citizens' moral quality and civilization quality is scientific, embodying the inheritance of traditional culture and the relevance of world trends and the care for real life. On the other hand, socialist core values (object) as an ideology satisfies the needs of the people's survival and development (the needs of the subject), which creates the relationship between the needs and satisfaction of the subject and the 
object. That is the value. It should be said that this is the key to improve the public's moral quality and civilization quality in the context of socialist core values.

\section{PRACTICING THE SOCIALIST CORE VALUES AND IMPROVING CITIZENS' MORAL QUALITY AND CIVILIZATION QUALITY AT THE GRASS-ROOTS LEVEL}

At present, there are relatively few forms and channels for integration into the main channels. Therefore, the academic community urgently needs to strengthen the socialist core values, enhance the research on the path of citizens' moral quality and civilization, and provide them with theoretical and practical guidance.

\section{A. Constructing an Education and Training System}

The country should pay attention to the integration of socialist core values education and ideological and political education, strengthen scientific research, realize the achievements of civic education of the socialist core values, refine the content of socialist core values on citizens' education, and dailyize the theoretical system.

\section{B. Adhering to Multi-pronged Coordinated Operations}

We must pay attention to "cooperation" and adhere to a multi-pronged approach to fully mobilize party and government agencies, propaganda departments, league members' organizations, social organizations, and communities to participate in the joint efforts. They can perform their duties, shoulder their responsibilities, and promote their own development. They would coordinate with each other, and cooperate with each other to ensure the practice of socialist core values. Also, it can enhance the moral quality and civilization quality of citizens with the strongest momentum and maximum synergy.

\section{Expanding the Awareness and Recognition of Values}

It should innovate propagation forms of citizens' socialist core values. It plays a leading role for outstanding citizens. And it can integrate citizen's socialist core values education and daily work. Then, it popularizes, concertizes, and universalizes the contents and requirements of core values, expanding citizens' recognition.

\section{Formulating Long-term Mechanism Guarantee}

To cultivate and practice the socialist core values is a long-term and systematic project that requires the mobilization of the entire society to participate in. It also requires the establishment of a long-term mechanism for nurturing and practicing. Combining with the characteristics of citizens, we must formulate cooperation and exchange mechanisms, incentive and restraint mechanisms, and institutional guarantee mechanisms that meet the actual socialist core values education of citizens. And it can ensure the implementation of socialist core values, and enhance the effectiveness and longevity of citizens' civilization quality and moral quality.

\section{E. Creating Good Atmosphere}

It is inseparable from the influence of a good environment to practice socialist core values and improve citizens' moral quality and civilization quality. It should comprehensively use various means to combine advocacy with opposition, guidance and restraint. And we can adhere to positive public guidance, excellent cultural attraction, and advanced exemplary guidance. We should give full play to the support and promotion role of citizens' moral quality and civilization quality, carry out rich and varied citizen activities, build citizens' socialist core values, enhance citizens' civilization quality and moral quality, and actively create favorable atmosphere conducive to the cultivation of socialist core values.

\section{F. Conscientiously Practicing Social Practice Activities}

It should actively explore the socialist core values education and integrate it into grassroots social practice activities. It could organize grassroots activities such as loving education, voluntary blood donation, respecting the elderly, community obligations, compassion donation, and public welfare plan. And it can take socialist core values as important assessment criteria. People should consciously practice the socialist core values in social practice. And it would enhance the moral quality and civilization quality of citizens.

\section{CONCLUSION}

Under the background of socialist core values, we must clearly realize the path for citizens to improve their moral quality and civilization quality. From national strategic perspective, it should build dynamic socialist core values, and enhance the cultivation of citizens' moral quality and civilization quality. Then, it would achieve the purpose socialist core values.

\section{REFERENCES}

[1] Wang Yonggui. The orientation and realization path of the cultivation of socialist core values [J]. Ideological and Theoretical Education, 2013(3).

[2] Zheng Jingjing et al. Multi-level interpretation and path exploration of mass identity of socialist core values[J]. Contemporary World and Socialism, 2016(3)

[3] Zou Shaoqing et al. The realistic dilemma and practical approaches to the cultivation of socialist core values in the era of big data[J].Marxism Research,2016(9). 